European parliament have fully signed up to this mission.

Nonetheless, the young agency's leadership can expect to take some political heat if, as is likely, most of its grants go to those EU countries that are already most established scientifically. A comparable dilemma has been encountered in the past by the US National Science Foundation (NSF), an agency that, perhaps more than any other, the ERC seeks to emulate. NSF grants have always flowed disproportionately to certain states, such as Massachusetts and California, where US scientific excellence is most heavily concentrated. The agency has dealt with the political challenge that this presents by publishing reams of relevant data upfront, while developing programmes (at the prompting of Congress) that assist researchers in the states that do less well with their applications. It has done this without compromising its criteria for grant selection.

One of the council's top priorities is to make sure that it establishes a reputation for excellence in its processes. It must do this to win the solid support of European scientists ahead of its first formal evaluation by the EU authorities, which will take place in just two years' time. For now, the council is still negotiating the details of the final EU executive agency within which it will eventually operate. Evaluation of grant proposals, meanwhile, is being overseen by a modest number of staff, most of whom have been seconded from national research agencies.

It is in this fragile context that the ERC is eager to avoid rocking political boats by publishing a national breakdown of who is being considered for its first grants. Instead, it has broken down the shortlist into the groups of nations that joined the EU at different stages of its evolution.
So it has revealed that $45 \%$ of the applicants, and $53 \%$ of the winners, come from Belgium, Germany, France, Italy, Luxembourg and the Netherlands - the six original members of the European Economic Community, as it was then known. The nine countries that joined after 1973, but before the entry of the former communist states, account for $36 \%$ of applications and $27 \%$ of the winners. The 12 members who have joined since 2004 did not do so well, putting in 9\% of the applications and winning 5\%. (Nine 'associated countries', such as Russia and Israel, as well as participants from farther afield account for the rest of the applications.)

Policy-makers might benefit from fuller information about the geographical distribution of both those who apply and those who make the shortlist, if only as a snapshot of how excellence in European science is currently distributed.

$$
\text { And according to its mission }
$$

"Ultimately, a commitment to transparency will have to override the European Research Council's concerns about giving offence." statement, the ERC is "committed to providing public information about its activities in a transparent and timely manner". Ultimately, that commitment to transparency will have to override the council's concerns about giving offence.

EU politics, in its complexity and fickleness, is likely to pose challenges for the new research agency at some stage. But Europe needs the ERC to be openly committed to uncompromising selection of the best. Sooner, rather than later, the ERC needs to commit to full publication of data on its selection processes, to defend these processes to the full, and to let the political chips fall where they may.

\section{Men [sic]}

\section{Our 1869 mission statement is out of date.}

t was 1833 when the English polymath William Whewell first coined the word 'scientist'. Over subsequent decades, the word gradually replaced such commonly used terms as 'natural philosophers' and 'men of science'.

By the middle of the nineteenth century, this last phrase was already out of date: pioneering women such as Mary Fairfax Somerville and Caroline Herschel were proving their worth as astronomers, mathematicians, botanists and palaeontologists.

The original mission statement of this journal, first printed in Nature's second issue on 11 November 1869, was therefore running behind the times when it referred to "Scientific men" - even though, to be fair, the word 'scientist' did not enter general circulation until the end of the nineteenth century. In other respects it is well worded - which is why we print it every week in the Table of Contents.

The statement expresses two purposes for this publication. The first is "to place before the general public the grand results of Scientific Work and Scientific Discovery; and to urge the claims of Science to a more general recognition in Education and in Daily Life". Today this is as important as it has ever been - although members of the public have important considerations to lay before scientists, and Nature reflects them also.

The second thrust was expressed as follows: "to aid Scientific men themselves, by giving early information of all advances made in any branch of Natural knowledge throughout the world, and by affording them an opportunity of discussing the various Scientific questions which arise from time to time."

In printing the statement verbatim every week as we have done, making it clear when it originated, we have hitherto assumed that readers will excuse the wording in the interests of historical integrity. But feedback from readers of both sexes indicates that the phrase, even when cited as a product of its time, causes displeasure. Such signals have been occasional but persistent, and a response is required.

There is a convention within the English language by which writers quoting text can indicate their view that a particular phrase is inappropriate. That is to insert sic, a Latin word meaning 'thus', after the phrase - in effect expressing the sentiment 'alas, dear reader, this is what was said?.

This is what we will do in the mission statement from now on. The small, belated change takes place against the vast backdrop of a scientific world where the upper echelons of academia, academies and prestigious awards are still numerically greatly dominated by men, and where outright discrimination can still rear its ugly head (see page 749). In this context, the insertion of a Latin word in a couple of paragraphs may be a tiny step: but it is at least one in the right direction. 